\title{
Direct endoscopic percutaneous jejunostomy placement with double balloon enteroscopy
}

Direct percutaneous endoscopic jejunostomy (DPEJ) provides an alternative modality of enteral feeding when percutaneous endoscopic gastrostomy (PEG) insertion is not feasible $[1,2]$. It also has a reduced risk of complications, including aspiration, when compared with PEG [3]. The success rate of DPEJ is reportedly only $68 \%$, mainly secondary to inadequate transillumination or failure to pass the scope into the jejunum [4]. Serious complications, including intestinal perforation and bleeding, are also reported on removal of DPEJ by manual traction $[4,5]$. We report the first case of successful DPEJ insertion by double balloon enteroscopy (DBE), and successful subsequent DPEJ tube change by DBE.

A 25-year-old man with oropharyngeal dysphagia due to hypoxic brain injury underwent PEG insertion for long-term enteral feeding. However, the patient required recurrent prolonged hospital admissions for treatment of severe aspiration pneumonia. A trial of jejunal feeding was considered.

After the PEG tube was removed, a DPEJ was placed using DBE. The enteroscope was passed anterograde into the jejunum until an ideal position was identified by adequate transillumination and finger invagination (approximately $1.5 \mathrm{~m}$ distal to the pylorus). Both balloons were inflated and a 21-gauge "finder needle" was inserted into the jejunal lumen and grasped by a snare to secure the position. The DPEJ tube was then placed using a 20-Fr pull method PEG tube kit using a modified technique as previously described [4]. On review at 24 months no local complications had occurred, the patient's nutritional status remained stable, and there had been a dramatic decrease in number of hospital admissions. At this time the external DPEJ tube was worn. In an uneventful procedure, the tube was removed and exchanged for a balloon-type

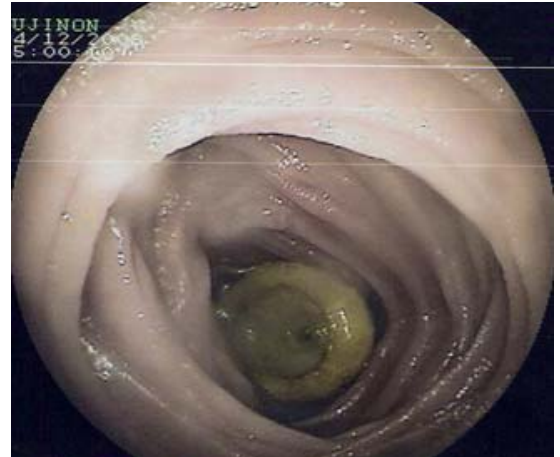

Fig. 1 Jejunostomy site identified on repeat anterograde double balloon enteroscopy.

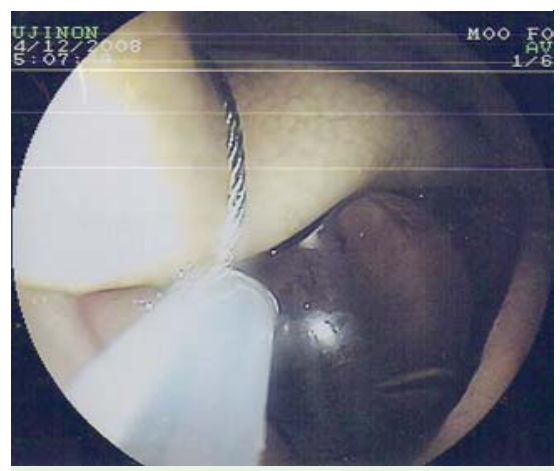

Fig. 2 Simultaneous removal of internal bumper of old jejunostomy tube and inflation of balloon and positioning of new feeding tube via double balloon enteroscopy under direct endoscopic vision.

PEG/J button, again using anterograde DBE ( Figs. 1 and 2).

In conclusion, utilization of DBE provides access to more distal parts of the jejunum and maximizes the chance of identifying an ideal DPEJ insertion site; it also allows safe exchange of the DPEJ tube. Future studies are awaited to compare the success rates, complication rates (in particular aspiration risk), and clinical outcomes (including nutritional status) between DPEJ by push enteroscope or colonoscope and DBE.
Endoscopy_UCTN_Code_TTT_1AO_2AK Endoscopy_UCTN_Code_TTT_1AP_2AD

\section{K. K. Yan, M. I. Kelly, D. S. Samuel}

Department of Gastroenterology,

Bankstown Hospital, Bankstown, Sydney, New South Wales, Australia

\section{References}

1 Del Piano M, Ballare M, Carmagnola $S$ et al. DPEJ placement in cases of PEG insertion failure. Dig Liver Dis 2008; 40: 140 - 143

2 Shike M, Schroy P, Ritchie MA et al. Percutaneous endoscopic jejunostomy in cancer patients with previous gastric resection. Gastrointest Endosc 1987; 33: 372 - 374

3 Panagiotakis PH, DiSario JA, Hilden $K$ et al. DPEJ tube placement prevents aspiration pneumonia in high-risk patients. Nutr Clin Pract 2008; 23: 172 - 175

4 Maple JT, Petersen BT, Baron TH et al. Direct percutaneous endoscopic jejunostomy: outcomes in 307 consecutive attempts. Am J Gastroenterol 2005; 100: 2681 - 2688

5 Zschau N, Nguyen N, Tam W, Schoeman M. Intestinal perforation: a rare complication of percutaneous endoscopic jejunostomy removal. Endoscopy 2008; 40 (Suppl 2): E178

Bibliography

DOI 10.1055/s-0029-1214775

Endoscopy 2010; 42: E43

(c) Georg Thieme Verlag KG Stuttgart · New York . ISSN 0013-726X

Corresponding author

D. S. Samuel, MMed (Clin. Epi.), FRACP

Department of Gastroenterology

Bankstown Hospital

Eldridge Road

Bankstown

NSW 2200

Australia

Fax: +61-2-97227752

gastromail@gmail.com 